\title{
Spatial and temporal characteristics of cancer in the period from 2004 to 2013 in the Hashemite Kingdom of Jordan
}

\author{
Salahuddin M. Jaber, ${ }^{1}$ Jwan H. Ibbini, ${ }^{2}$ Nawal S. Hijjawi, ${ }^{3}$ Juhina J. Thnaibat, ${ }^{4}$ Omar F. Nimri ${ }^{5}$ \\ ${ }^{1}$ Department of Water Management and Environment, Faculty of Natural Resources and Environment, \\ Hashemite University, Zarqa; ${ }^{2}$ Department of Land Management and Environment, Faculty of Natural \\ Resources and Environment, Hashemite University, Zarqa; ${ }^{3}$ Department of Medical Laboratory Sciences, \\ Faculty of Allied Health Sciences, Hashemite University, Zarqa; ${ }^{4}$ Department of Environmental Studies and \\ Planning, Greater Amman Municipality, Amman; ${ }^{5}$ Cancer Prevention Department, Jordan Cancer Registry, \\ Ministry of Health, Amman, Hashemite Kingdom of Jordan
}

\begin{abstract}
Cancer in Jordan is a major public health problem and the second leading cause of death after heart disease. This study aimed at studying the spatial and temporal characteristics of cancer in Jordan and its 12 governorates for the period 2004-2013 to establish a baseline for future research and identification of cancer risk factors paving the way for developing a cancer control plan in the country. Numerical and graphical summaries, time-series additive seasonal decomposition, the method of least squares, and spacetime scan statistics were applied in a geographic information systems environment. Although the results indicate that the cancer incidence in Jordan is comparatively low, it is increasing over time. In the 10-year study period, a total of 44,741 cases was reported with a mean annual crude incidence rate of 68.4
\end{abstract}

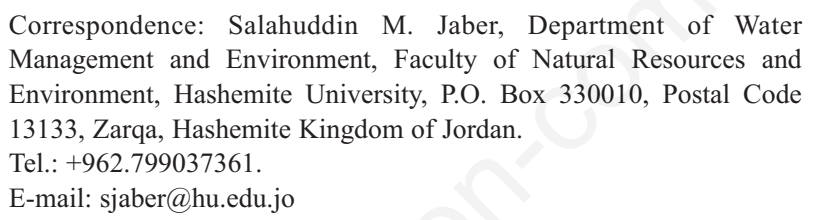

Key words: Cancer; Disease mapping; Spatial analysis; Temporal analysis; Jordan.

Contributions: the authors contributed equally.

Conflict of interest: the authors declare no potential conflict of interest.

Funding: none.

Received for publication: 24 March 2018 .

Revision received: 31 August 2018.

Accepted for publication: 12 September 2018.

(C) Copyright S.M. Jaber et al., 2018

Licensee PAGEPress, Italy

Geospatial Health 2018; 13:695

doi:10.4081/gh.2018.695

This article is distributed under the terms of the Creative Commons Attribution Noncommercial License (CC BY-NC 4.0) which permits any noncommercial use, distribution, and reproduction in any medium, provided the original author(s) and source are credited. cases/100,000, mean annual age-adjusted incidence rate of 111.9 cases/100,000, and a monthly rate increase of 1.2 (cases/100,000)/month. This study also revealed that the spatial and temporal characteristics of cancer vary among the governorates. Amman, which includes the capital city and hosts more than one-third of the population of the country, reported $61.0 \%$ of the total number of cases. Amman also reported the highest annual crude incidence rate $(105.3$ cases/100,000), the highest annual age-adjusted incidence rate $(160.6$ cases/100,000), and the highest rate of increase $(0.7$ (cases/100,000)/month) forming a high-rate cluster. Excluding the three governorates Amman, Balqa, and Ma'daba, low-rate clusters were found with regard to the remaining governorates. All governorates, except Irbid and Mafraq, showed significant rates of increase of cancer incidence. However, no clear seasonality pattern with respect to cancer incidence was discerned.

\section{Introduction}

Cancer is continuously regarded as the second leading cause of death after heart disease (John and Ross, 2010; King Hussein Cancer Center, 2017; National Cancer Institute (NCI), 2017; Roquette et al., 2017; World Health Organization, WHO, 2017). Globally, every year, millions of people are diagnosed with cancer and the number of new cases is expected to rise by $70 \%$ over the next two decades (WHO, 2017). According to the International Agency for Research on Cancer (IARC, 2018), the worldwide overall cancer age-adjusted incidence rates in 2012 were 205 cases/100,000 for males and 165 cases/100,000 for females. The agency also noticed large differences among the various countries in the world according to their classifications as high-income, middle-income, and low-income. Geographically for males, the rates varied from 79 cases/100,000 in Western Africa to 365 cases/100,000 in Australia/New Zealand, while, for females, the rates varied from 103 cases/100,000 in South-Central Asia to 295 cases/100,000 in North America. Cancer in Jordan is a major public health problem with enormous social, economic, and environmental impact, and it can worsen since the young population today has a longer life expectancy associated with prolonged exposure to risk factors (Abdel-Razeq et al., 2015). Although many countries have developed national action plans for controlling cancer and ameliorating its burden, some of which have been translated into fully operational interventions (WHO, 2015), Jordan has so 
far not developed national cancer control action plan of its own. However, in order to develop and implement such a plan, there is a need to study the spatial and temporal characteristics of cancer. This should be done in a geographic information systems (GIS) environment since this approach provides an ideal platform for conducting such research. Indeed, the scientific literature points out many studies conducted in various parts of the world in order to address the spatial and temporal characteristics of several types of cancer in a GIS environment. Examples include prostate cancer in Pennsylvania, United States (Hayran, 2004), malignant neoplasm of the pancreas in Japan (Kinoshita et al., 2007), lung cancer in Lecce Province, Italy (Bilancia and Fedespina, 2009), oesophageal cancer and gastric cancer in Iran's Caspian region (Mohebbi et al., 2011), cervical cancer in San Luis Potosi State, Mexico (Teran-Hernandez et al., 2016), and thyroid cancer in Belgium's Walloon and Flemish regions, including Brussels (Demoury et al., 2017).

In Jordan, studying the spatial and temporal characteristics of diseases using GIS is not an active area of research apart from a few studies on cutaneous leishmaniasis (Jaber et al. 2013; 2014). The two above-mentioned studies were the first to merge the two disciplines of GIS and epidemiology in the country. The existing literature in Jordan on various diseases including cancer concentrate only on epidemiology applying simple summary statistics (Ajlouni et al., 1998; Khader, 2006; Abu-Baker et al., 2010; AlTarawneh et al., 2010; Tarawneh et al., 2011; Basheti et al., 2013; Ismail et al., 2013; Abdel-Razeq et al., 2015; Tayyem et al., 2015; Haddad et al., 2017). The present study aimed at filling this gap by studying the spatial and temporal characteristics of cancer in Jordan in a GIS environment, as such work would establish a baseline for future research of this kind. In our opinion, this approach should help in the identification of cancer risk factors in the country paving the way for decision-makers to develop and implement a science-based cancer control action plan in Jordan.

\section{Materials and Methods}

\section{Study area}

Jordan (Figure 1), a Middle Eastern Kingdom situated between latitudes $29^{\circ} \mathrm{N}$ and $34^{\circ} \mathrm{N}$ and longitudes $34^{\circ} \mathrm{E}$ and $40^{\circ} \mathrm{E}$, has an area of about $88,780 \mathrm{~km}^{2}$ and an estimated population (including Jordanians and immigrants) at the end of 2016 of about 9,798,000. Administratively, it is divided into three regions and 12 governorates. The northern region comprises Irbid, Ajlun, Jarash, and Mafraq governorates. The central region comprises Balqa, Amman, Zarqa, and Ma'daba governorates. The southern region comprises Karak, Tafiela, Ma'an, and Aqaba governorates. With an area of about $32,829 \mathrm{~km}^{2}$, Ma'an is the largest governorate, while Jarash is the smallest (about $406 \mathrm{~km}^{2}$ ). About $42 \%$ of the population is concentrated in Amman Governorate, which includes the capital city Amman. With about 1\% of the total population, Tafiela Governorate is the most sparsely populated. The country has an East Mediterranean climate type with hot dry summers and cold humid winters. This information was obtained from the Department of Statistics of Jordan (Department of Statistics of Jordan, DOS, 2016).

\section{Cancer data}

Reported monthly data on cancer occurrence in the Jordanian population in the 12 governorates for the period 2004-2013 were obtained from the published annual governmental reports of the Jordan Cancer Registry (JCR) ((Jordan Cancer Registry, JCR, 2016). Monthly cancer cases counts were aggregated to obtain annual cancer cases counts and then were used to calculate crude annual cancer incidence rates per 100,000 by applying Eq. 1 below:

$$
I R_{i}=\frac{C C_{i}}{P_{i}} \times 100,000
$$

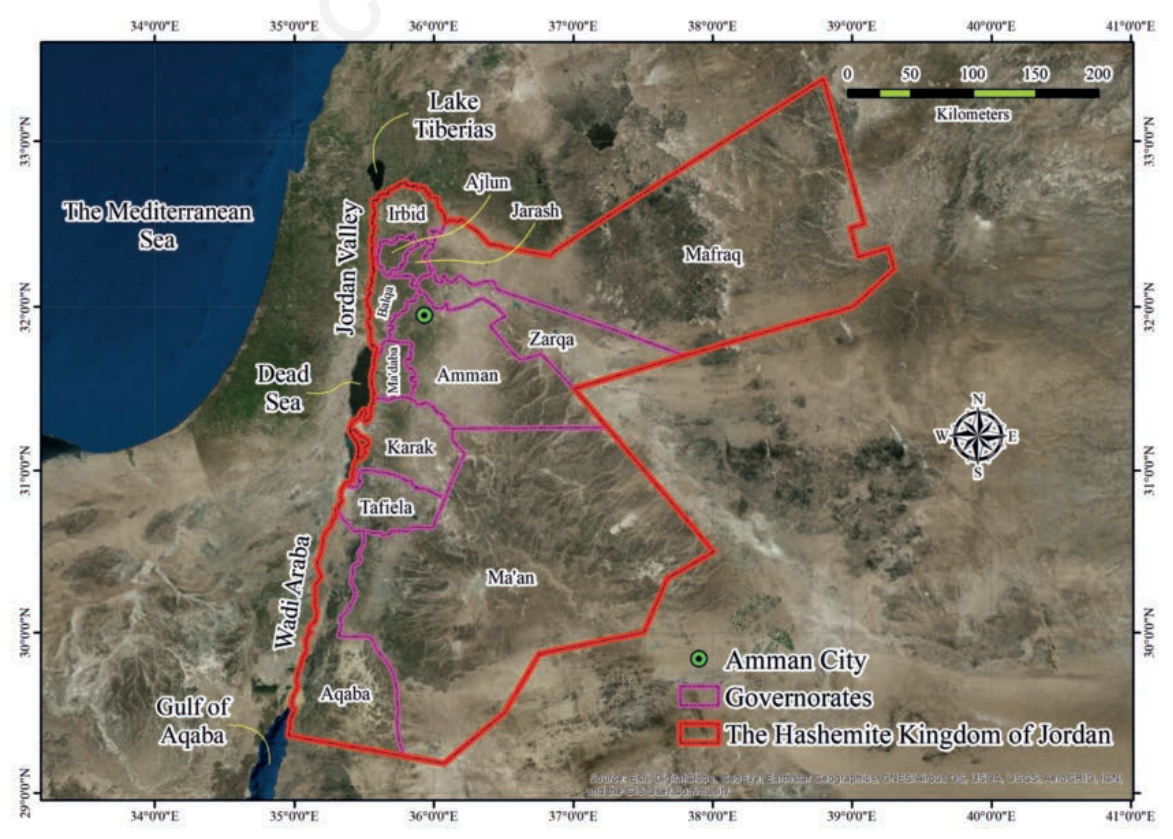

Figure 1. Location map of Jordan showing its 12 governorates and Amman, the capital city. 
where $I R_{i}$ is the crude cancer incidence rate per 100,000 for Jordan and its 12 governorates in year $i, C C_{i}$ the cancer cases counts reported for Jordan and its 12 governorates in year $i$, and $P_{i}$ the population of Jordan and its 12 governorates in year $i$.

In order to eliminate the effect of differences in population age structures, the annual cancer age-adjusted incidence rates per 100,000 were calculated. This is specifically important when comparing different periods of time, different geographic areas, and/or different populations. The direct method was implemented as shown in Eq. 2 below using the WHO world standard population (Ahmad et al., 2001):

$$
A A I R_{i}=\frac{\sum\left(A S I R_{i j} \times W S P_{j}\right)}{\sum W S P_{j}}
$$

where $A A I R_{i}$ is the cancer age-adjusted incidence rate per 100,000 for Jordan and its 12 governorates in year $i, A S I R_{j}$ the cancer agespecific incidence rate per 100,000 for Jordan and its 12 governorates for age group $j$ in year $i$, and $W S P_{j}$ the WHO world standard population for age group $j$.

\section{Numerical and graphical summaries}

Numerical and graphical summaries for annual cancer cases counts, annual cancer crude incidence rates, and annual cancer age-adjusted incidence rates for Jordan and its 12 governorates for the period 2004-2013 were generated. Numerical summaries were represented by measures of central tendency (i.e., Mean) and measures of dispersion (i.e., minimum (Min) and maximum (Max)), while the graphical summaries were represented by time-series scatter plots and maps.

\section{Time-series additive seasonal decomposition and method of least squares}

Additive seasonal decomposition (Hyndman and Athanasopoulos, 2014) is a decomposition technique for timeseries data. It assumes that the original time series $(\mathrm{Y})$ is expressed as the sum of four components: trend (T), cycle (C), seasonal (S), and irregular (I). It is expressed by Eq. 3 below:

$Y_{t}=T_{t}+C_{t}+S_{t}+I_{t}$

where $Y_{t}$ is the observed data at time $t$ and $T_{t}, C_{t}, S_{t}$, and $I_{t}$ the components at time $t$ as described earlier.

The trend component represents the general long-term pattern (i.e., increase or decrease) observed over the entire time of study. The cycle component represents relatively long-term cyclical variations around the trend line that are not of fixed period. Usually, these two components (i.e., trend and cycle) were combined into one since they both represent relatively long-term effects. The seasonal component represents relatively short-term cyclical variations around the trend line that are of fixed period influenced by seasonal factors (e.g., season, month, day of the week). Usually, the average cycle length is longer than that of seasons and the magnitude of cycles tends to be more variable than that of the seasons, which repeat on a regular and predictable basis. These three components (i.e., trend, cycle, and seasonal) represent the systematic component of the time series. The irregular component represents the residual random noise, which is the non-systematic component of the time series that cannot be modelled directly.

Based on a sampling interval of one month and a length of sea- sonality of 12 months and the total monthly cancer cases counts data for the years 2004-2013, we applied the time-series additive seasonal decomposition using Statgraphics Centurion XVI, v. 16.2.04 (Statgraphics Technologies Inc., USA http://www.statgraphics.com/). The decomposition divided the observed time series into its component parts, which were: i) estimate of the combined trend-cycle component; ii) seasonal indices representing the effect of each season (i.e., month); and iii) the residuals (i.e., irregular) component. In addition, simple linear regression using the method of least squares (Hansen et al., 2013) was applied on the trend-cycle components to explore their linear rates of change for every unit-of-time increase.

\section{Space-time scan statistics}

The space-time scan statistics (Kulldorff, 1997) implemented in SaTScan software, v. 9.4.4 (Information Management Services Inc., USA - https://www.satscan.org/) is widely used for detecting clustering of disease data using a cylindrical scanning window with height corresponding to time (Kulldorff, 2015). Under the null hypothesis of no significant clustering and the assumption that the disease data are random, independent and Poisson-distributed, the scanning window is moved in space and time. Hence, a large number of overlapping windows of various sizes and shapes are formed covering the entire study area. For each scanning window, the expected number of disease data is calculated according to the observed data and population data. The observed and expected number of disease data within and outside the scanning window are used to construct the test Log Likelihood Ratio (LLR). The scanning window with the maximum LLRs is identified as the most likely cluster; that is the cluster least likely to be due to chance. Using the Monte Carlo hypothesis testing method, the statistical significance (i.e., P-value) of that cluster is evaluated to whether reject or not reject the null hypothesis for typical cut-off value such as 0.05 . Secondary clusters, in addition to the primary most likely cluster, ordered according to their LLRs, are also identified.

Using the annual cancer cases counts during the total study period for the 12 governorates of Jordan as the Case File, the annual population data from 2004 to 2013 for the 12 governorates of Jordan as the Population File, and the geographic coordinates of the centroids of the 12 governorates as the Coordinates File, SaTScan was implemented to scan for high-rate and low-rate clusters of cancer in Jordan and its 12 governorates. Space-time retrospective analysis was applied. Poisson discrete scan statistics probability model, circular spatial scanning window shape, $50 \%$ of the population at risk as the maximum spatial cluster size, $50 \%$ of the study period as the maximum temporal cluster size, and 999 as the maximum number of Monte Carlo replications were selected for the analysis. Maps were produced to clearly represent the location and size of the generated clusters.

\section{Results}

Over the 10-year study period, a total of 44,741 cancer cases were reported in Jordan as a whole (Table 1; Figures 2-4). Almost exactly $61.0 \%$ of the cases were seen in Amman, followed by Irbid (13.6\%), and Zarqa (9.8\%), while the lowest number of cases was reported from Tafiela (only $0.7 \%$ of the total number of cases). The highest annual cancer crude incidence rate $(105.3$ cases/100,000) was calculated for Amman followed by Ma'daba (72.0 cases/100,000) and Balqa (71.8 cases/100,000), while the lowest rate was calculated for Mafraq (17.8 cases/100,000). Regarding the 
annual cancer age-adjusted incidence rates, nearly the same sequence as the one obtained for the annual cancer crude incidence rates was generated; i.e., the highest value was calculated for Amman (160.6 cases/100,000) followed by Ma'daba (124.4 cases/100,000) and Balqa (118.7 cases/100,000) with the lowest rate calculated for Mafraq (33.4 cases/100,000). For Jordan as a whole, the mean annual cancer crude incidence rate was 68.4 cases/100,000 with values varying from 62.4 cases/100,000 to 73.5 cases $/ 100,000$. The mean annual cancer age-adjusted incidence rate was 111.9 cases $/ 100,000$ with values varying from 100.0 cases/100,000 to 120.9 cases/100,000.

The results of applying time-series additive seasonal decomposition on the monthly cancer cases counts are shown in Figure 5. Visual inspection of the trend-cycle components for all the governorates, in addition to Jordan as a whole, show up and down movements over the whole 10-year period (Figure 5A). Looking at the scaled seasonal indices for each month (Figure 5B) it can be noticed that for the governorates Irbid, Jarash, Mafraq, Balqa, Amman, Zarqa, Tafiela, and Aqaba, in addition to Jordan as a whole, the highest values were reported in either June or July, while they were reported in April for the governorates Ajlun, Ma'daba, and Ma'an, and in October for Karak. The lowest values, on the other hand, were reported in either November or December for the governorates Irbid, Jarash, Mafraq, Balqa, Amman, Zarqa, Karak, and Ma'an, in addition to Jordan as a whole, while they were reported in September for Ajlun and Ma'daba and in March and August for Tafiela and Aqaba, respectively.

Applying the method of least squares on the trend-cycle components resulted in significant positive linear fits for all the governorates except for Irbid and Mafraq (Table 2). This indicates increasing trends in all the governorates except for these two northern governorates. The highest significant rate of increase $(0.7$ (cases/100,000)/month) was calculated for Amman followed by Zarqa (0.2 (cases/100,000)/month) and Balqa $(0.1$ (cases/100,000)/ month).

Table 1. Numerical summary with respect to cancer in Jordan and its 12 governorates in the period 2004-2013.

\begin{tabular}{|c|c|c|c|c|c|c|c|c|c|}
\hline \multirow[t]{2}{*}{ Governorate } & \multicolumn{3}{|c|}{$\begin{array}{c}\text { Cases } \\
\text { (total count) }\end{array}$} & \multicolumn{3}{|c|}{$\begin{array}{l}\text { Crude Incidence Rate } \\
\text { (cases/100,000) }\end{array}$} & \multicolumn{3}{|c|}{$\begin{array}{l}\text { Age-adjusted Incidence Rate } \\
\text { (cases/100,000) }\end{array}$} \\
\hline & Total & Min & Max & Mean & Min & Max & Mean & Min & $\operatorname{Max}$ \\
\hline Irbid & 6,065 & 501 & 662 & 50.463 & 38.577 & 59.315 & 85.806 & 63.306 & 102.903 \\
\hline Ajlun & 495 & 25 & 60 & 41.087 & 24.178 & 50.042 & 66.403 & 38.113 & 80.332 \\
\hline Jarash & 695 & 49 & 84 & 42.833 & 35.200 & 52.241 & 76.806 & 58.463 & 95.185 \\
\hline Mafraq & 866 & 60 & 123 & 23.137 & 17.844 & 33.874 & 46.127 & 33.445 & 68.127 \\
\hline Balqa & 1,911 & 85 & 259 & 55.837 & 28.620 & 71.807 & 90.586 & 44.308 & 118.679 \\
\hline Amman & 27,311 & 2,246 & 3,350 & 99.265 & 92.775 & 105.284 & 149.462 & 136.421 & 160.595 \\
\hline Zarqa & 4,365 & 237 & 533 & 46.494 & 29.569 & 59.150 & 79.333 & 51.112 & 100.531 \\
\hline Ma'daba & 792 & 39 & 101 & 60.539 & 35.104 & 72.044 & 98.248 & 53.419 & 124.442 \\
\hline Karak & 993 & 71 & 137 & 45.356 & 38.162 & 55.104 & 72.185 & 57.989 & 86.311 \\
\hline Tafiela & 307 & 16 & 42 & 45.954 & 28.321 & 62.043 & 81.010 & 47.468 & 107.377 \\
\hline Ma'an & 460 & 25 & 60 & 46.080 & 28.736 & 56.764 & 74.671 & 44.433 & 94.119 \\
\hline Aqaba & 481 & 29 & 76 & 36.674 & 24.784 & 47.441 & 70.123 & 43.856 & 94.071 \\
\hline Total in the country & 44,741 & 3,585 & 5,348 & 68.397 & 62.400 & 73.482 & 111.892 & 99.955 & 120.912 \\
\hline
\end{tabular}

Table 2. Results of least squares applied on the trend-cycle components with respect to cancer in Jordan and its 12 governorates in the period 2004-2013.

\begin{tabular}{|c|c|c|c|c|}
\hline Governorate & $a^{a}$ & $\mathbf{b}^{\mathrm{b}}$ & $\mathbf{R}^{2}$ & P-value \\
\hline Irbid & 50.0850 & 0.0073 & 0.0048 & 0.4769 \\
\hline Ajlun & 3.9097 & 0.0055 & 0.0883 & $0.0018^{*}$ \\
\hline Jarash & 5.0573 & 0.0140 & 0.3102 & $<0.0000^{*}$ \\
\hline Mafraq & 6.9732 & 0.0064 & 0.0223 & 0.1233 \\
\hline Balqa & 9.4353 & 0.1202 & 0.6739 & $<0.0000^{*}$ \\
\hline Amman & 186.0440 & 0.7473 & 0.8556 & $<0.0000^{*}$ \\
\hline Zarqa & 28.7877 & 0.1520 & 04614 & $<0.0000^{*}$ \\
\hline Ma'daba & 4.7977 & 0.0351 & 0.7231 & $<0.0000^{*}$ \\
\hline Karak & 5.7904 & 0.0446 & 0.7834 & $<0.0000^{*}$ \\
\hline Tafiela & 1.7586 & 0.0152 & 0.6464 & $<0.0000^{*}$ \\
\hline Ma'an & 2.4288 & 0.0271 & 0.8023 & $<0.0000^{*}$ \\
\hline Aqaba & 2.2791 & 0.0300 & 0.8006 & $<0.0000^{*}$ \\
\hline Total in the country & 307.3470 & 1.2047 & 0.8348 & $<0.0000^{*}$ \\
\hline
\end{tabular}

Intercept; ${ }^{\mathrm{a}}$ Slope or linear rate of change of $\mathrm{Y}$ associated with one-unit increase in $\mathrm{X}$; Fitting significant at the 0.05 level. The fitted linear equation had the form $\mathrm{Y}=\mathrm{a}+\mathrm{bX}$. 
A

Irbid

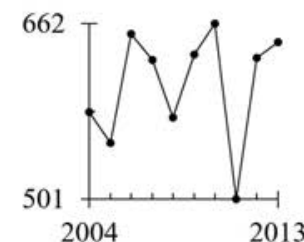

Ajlun
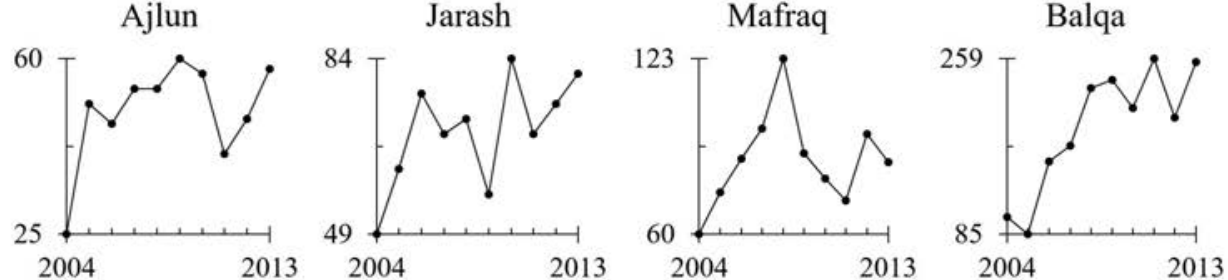

Amman

Zarqa

Ma'daba

Karak

Tafiela
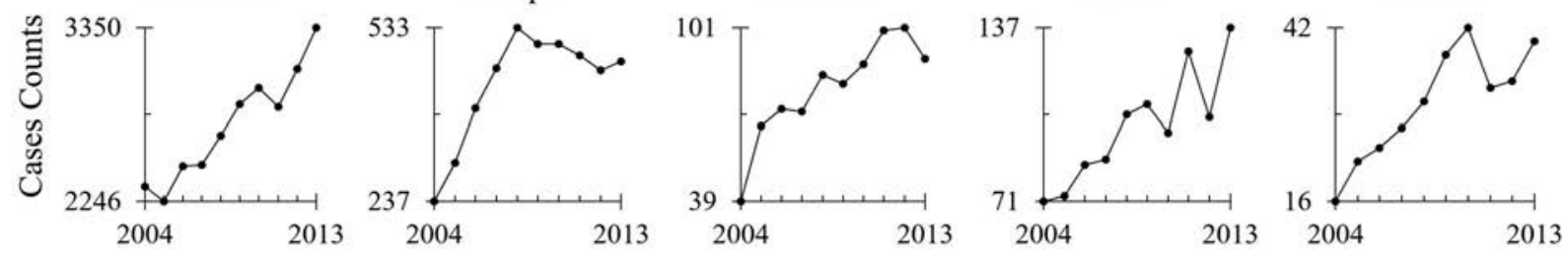

Ma'an

Aqaba
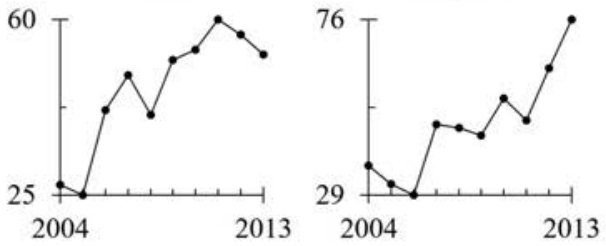

Jordan

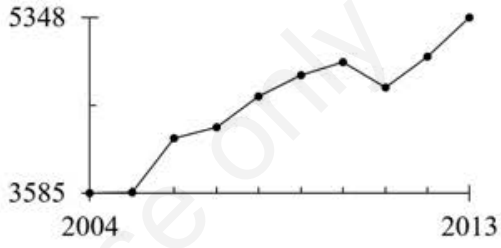

Year

B
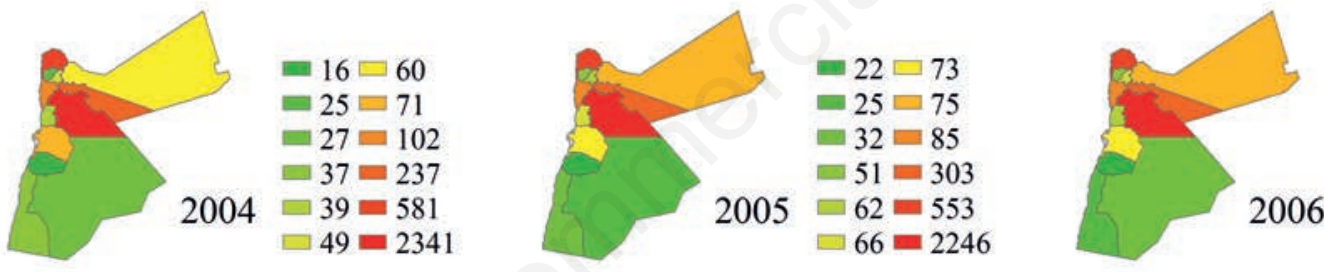

븐 $24 \square 85$

$-29 \square 87$

- $42=157$

$-47=396$

2006

$\square 72=653$
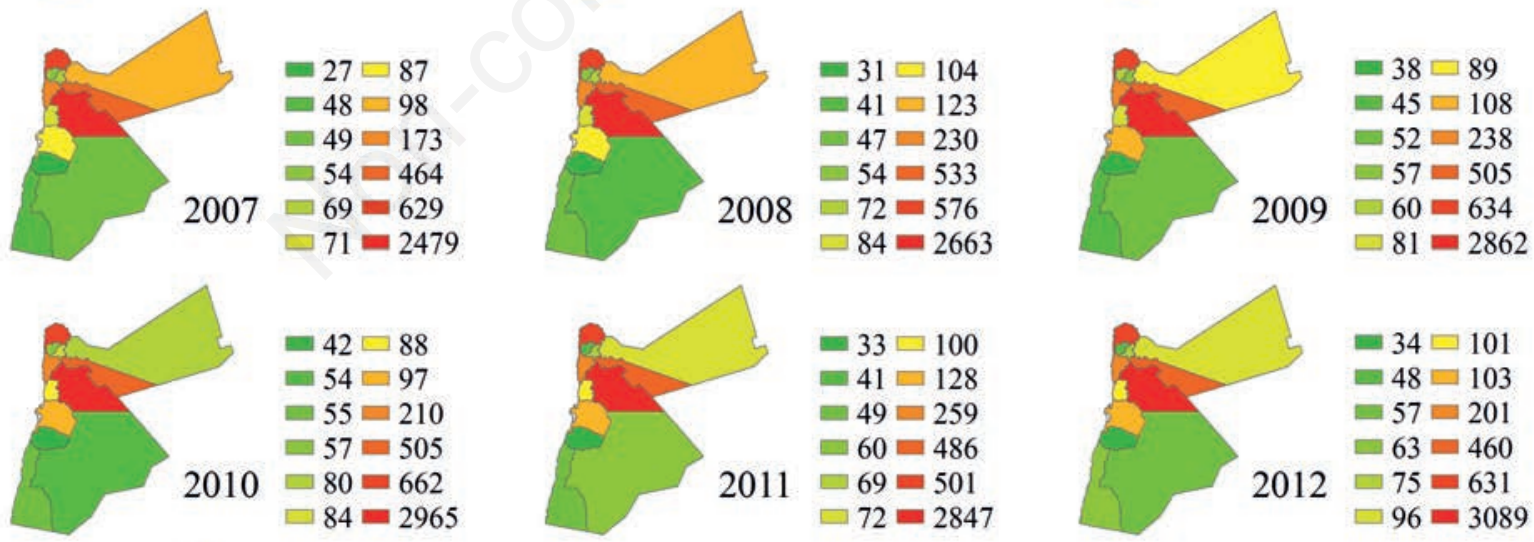

프 $34 \square 101$

믐 4803

- $57=201$

$-63=460$

2012

$\square 75=631$

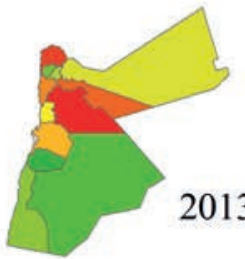

$-40 \square 90$

$-53 \square 137$

$-58=256$

$-76=476$

$2013 \square 81=645$

$\square 86=3350$
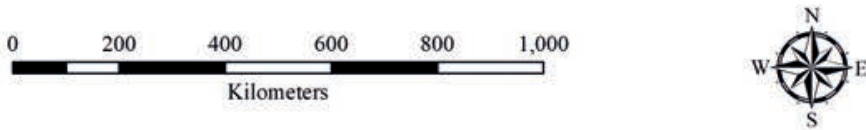

Figure 2. (A) Time-series scatter plots for annual cancer cases counts for Jordan and its 12 governorates in the period 2004-2013; (B) time-series maps showing the spatial distribution of the annual cancer cases counts for the 12 governorates of Jordan in the period 2004-2013. 

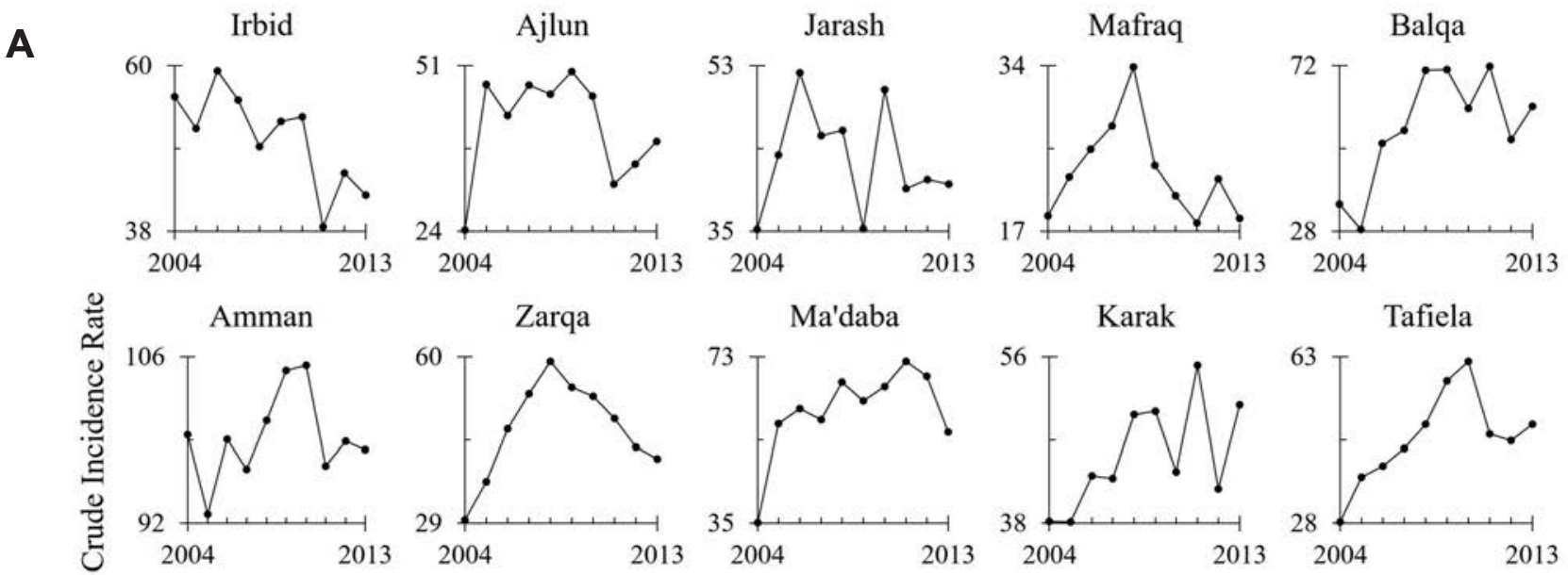

Ma'an

Aqaba

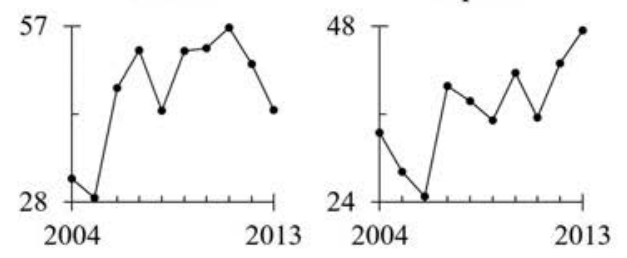

Jordan

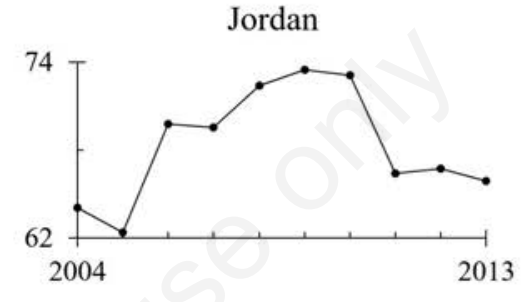

Year

B
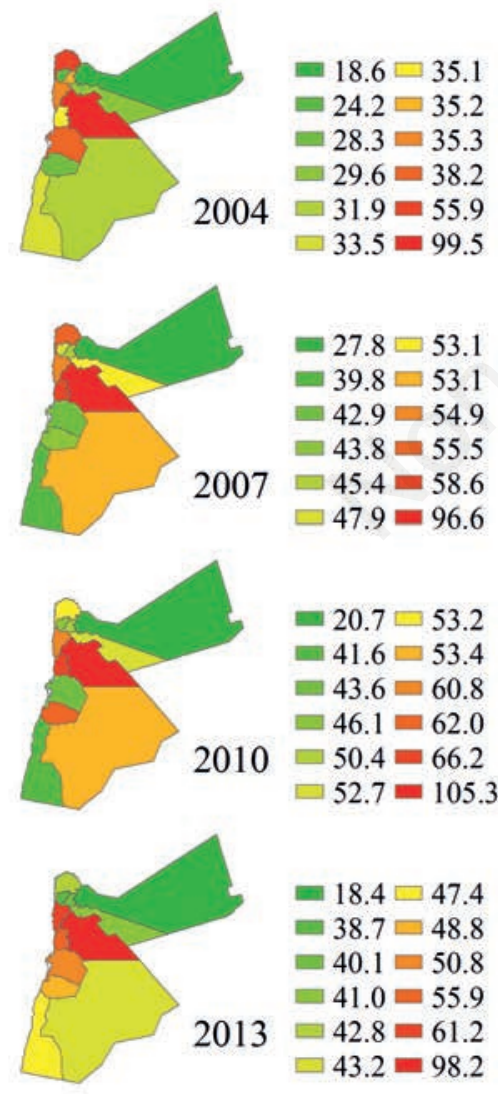

$=38.7 \square 48.8$

$-40.1=50.8$

$-41.0=55.9$

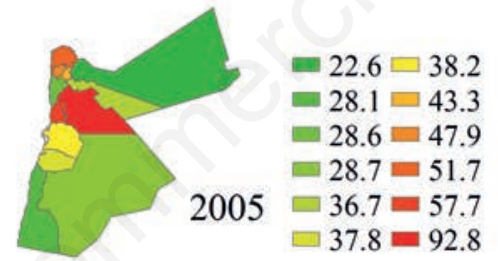

$=33.9 \square 49.3$

$-37.8 \square 49.8$

$-43.1=59.1$

$-46.0=67.3$

$2008-46.4=70.9$

$\square 48.7=100.6$

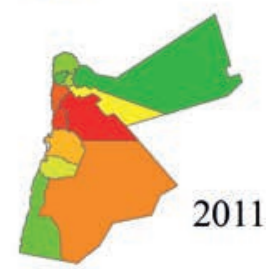

ㅁ $17.8 \square 48.5$

$-31.7 \square 55.1$

$-35.5=56.8$

$-38.6=71.8$

$2011-39.7=72.0$

$\square 46.7=96.8$
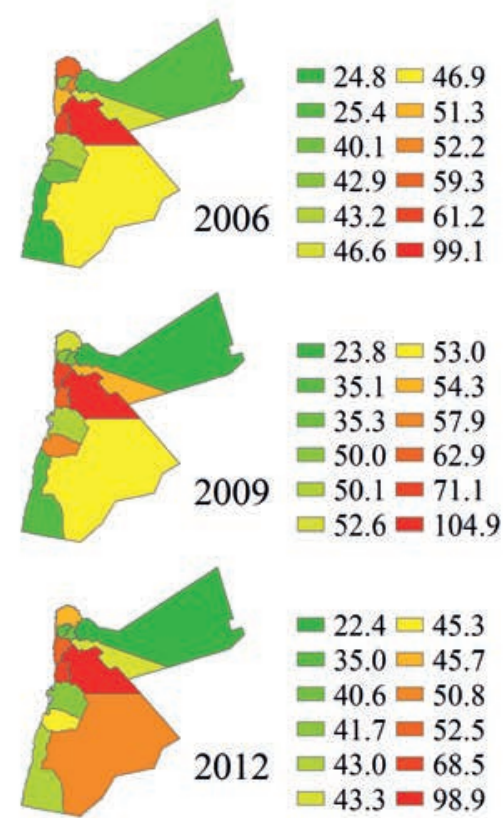

$=22.4 \square 45.3$

$=35.0 \square 45.7$

$=40.6=50.8$

$-41.7=52.5$

$2012-43.0=68.5$

$\square 43.3=98.9$

$-18.4 \square 47.4$
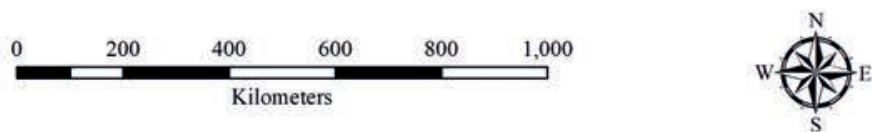

Figure 3. (A) Time-series scatter plots for the annual cancer crude incidence rates (cases/100,000) in Jordan and its 12 governorates in the period 2004-2013; (B) time-series maps showing the spatial distribution of the annual cancer crude incidence rates (cases/100,000) for the 12 governorates of Jordan in the period 2004-2013. 


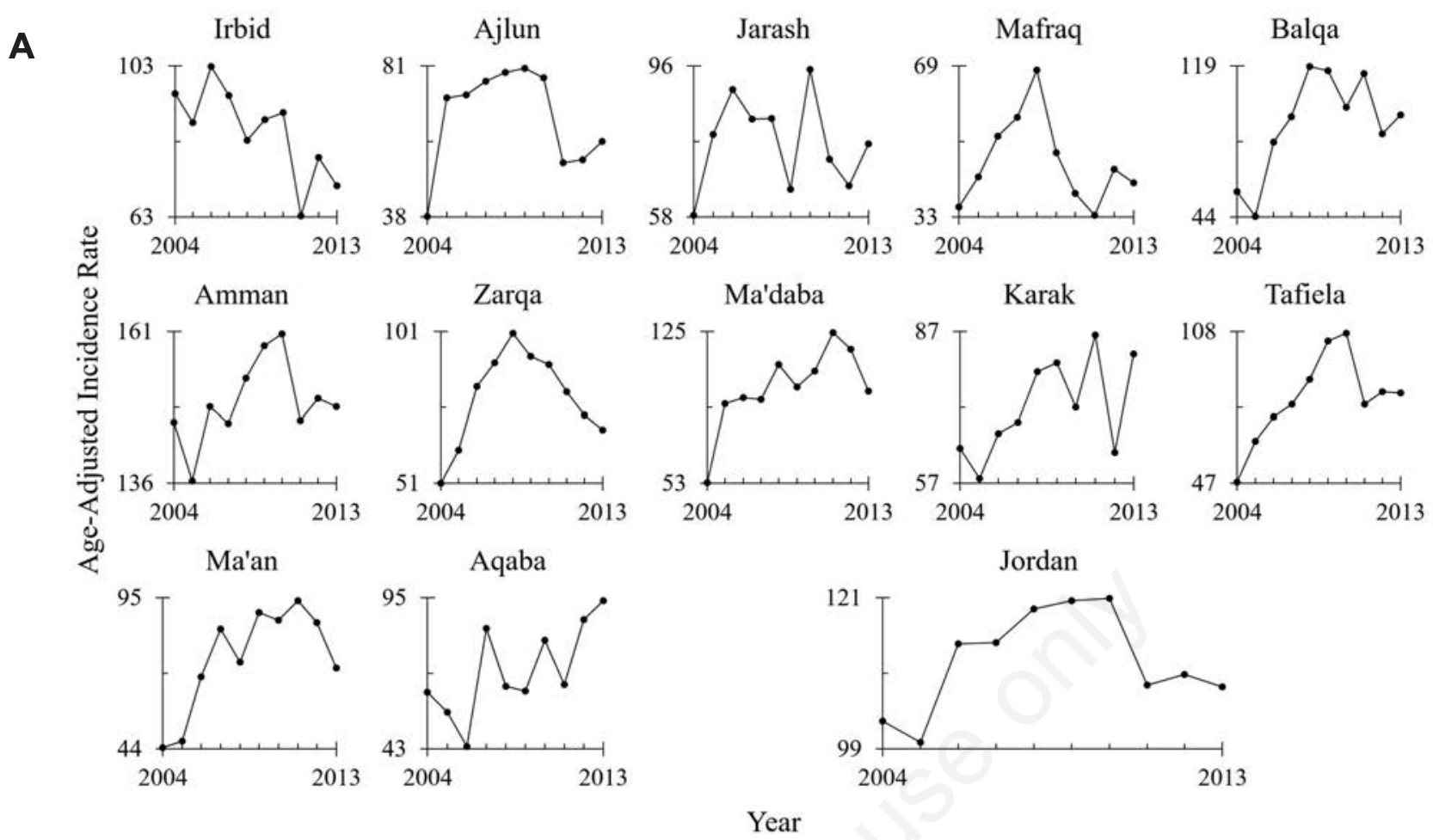

B
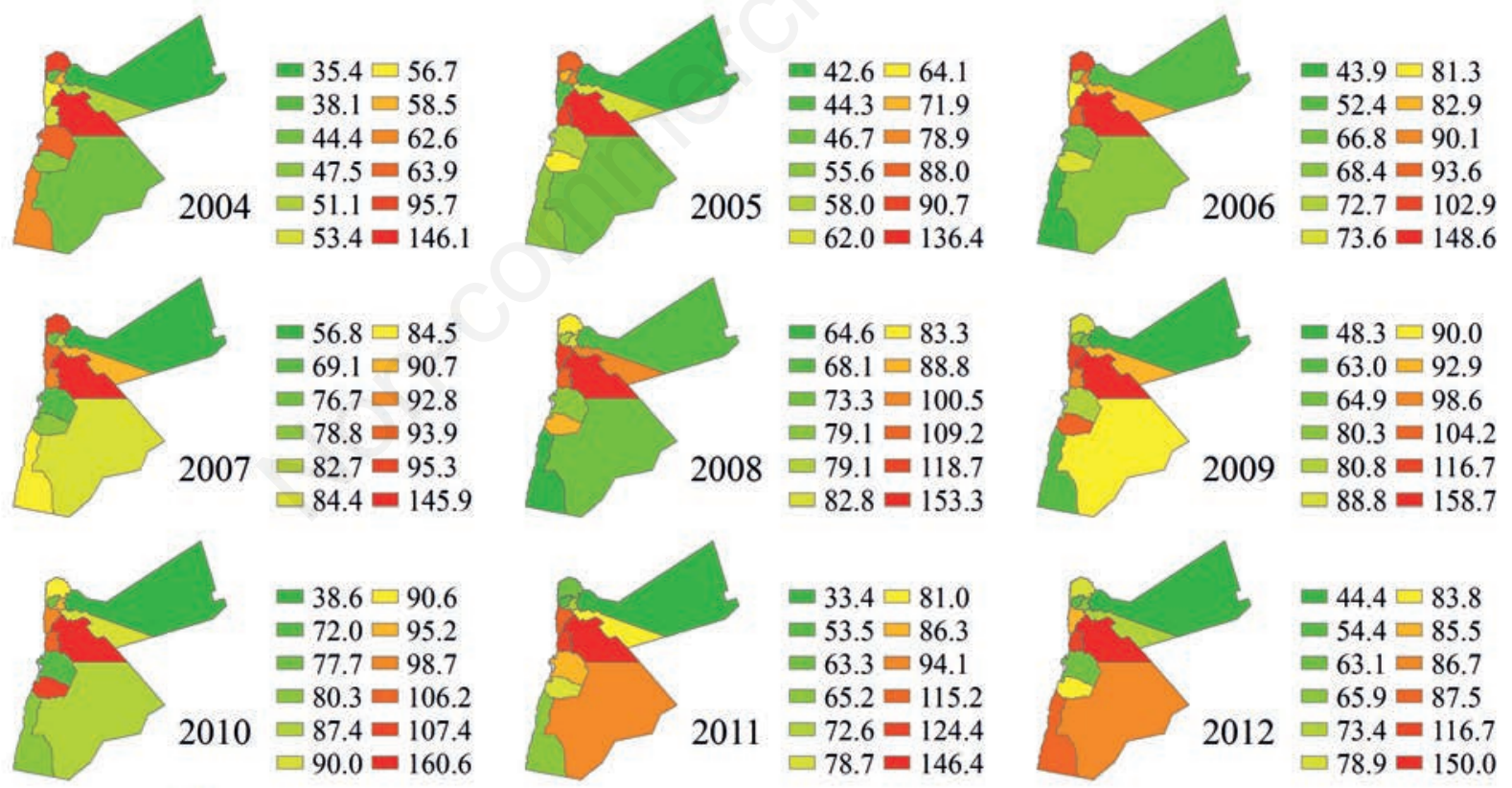

$\square 4.4 \square 83.8$

$=54.4 \square 85.5$

$=63.1=86.7$

$-65.9=87.5$

2012

$\square 73.4=116.7$

$\square 78.9=150.0$
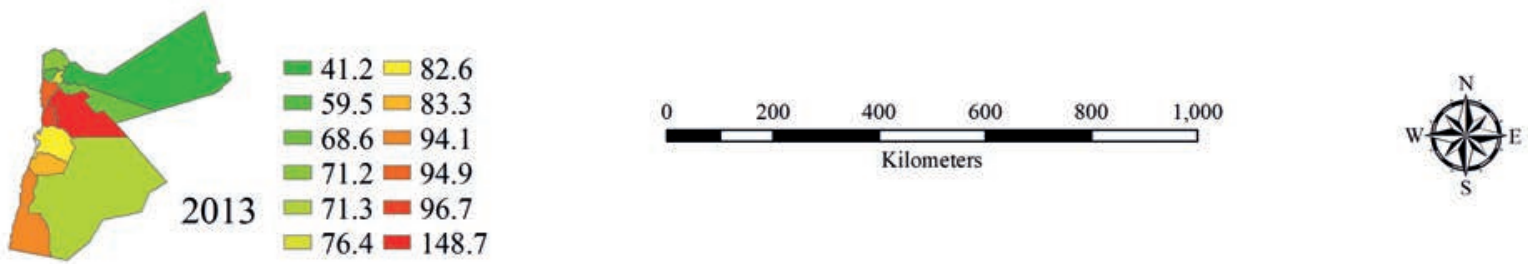

Figure 4. (A) Time-series scatter plots for the annual cancer age-adjusted incidence rates (cases/100,000) in Jordan and its 12 governorates in the period 2004-2013; (B) time-series maps showing the spatial distribution of the annual cancer age-adjusted incidence rates (cases/100,000) for the 12 governorates of Jordan in the period 2004-2013. 
A
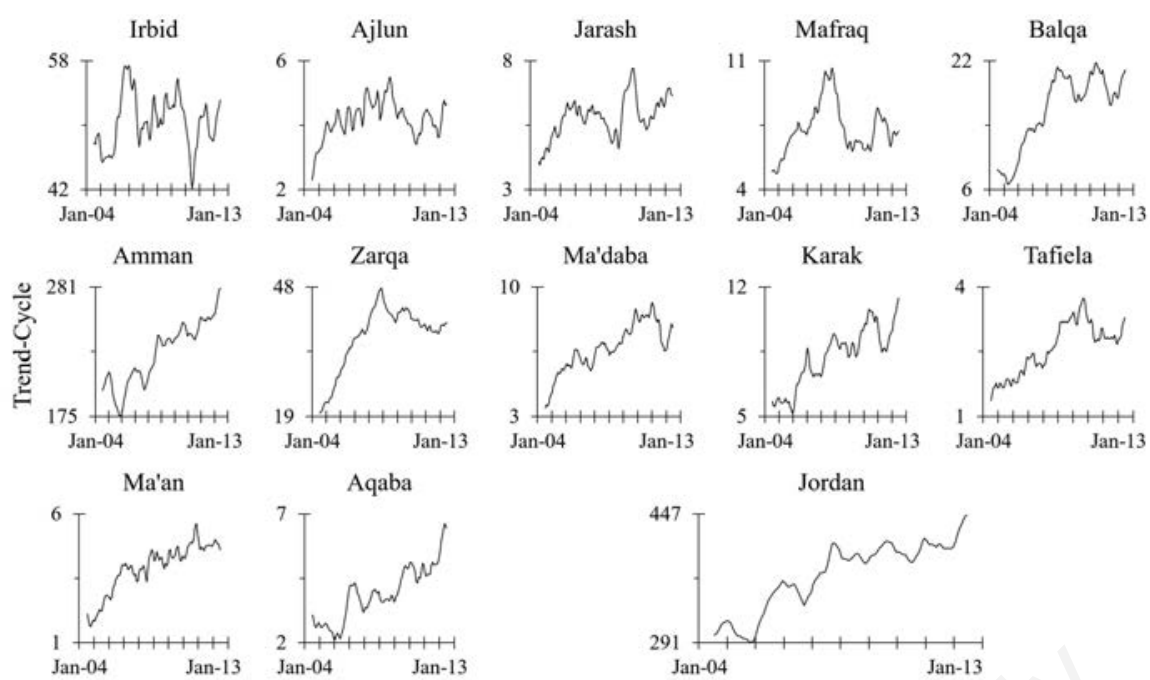

Month-Year

B
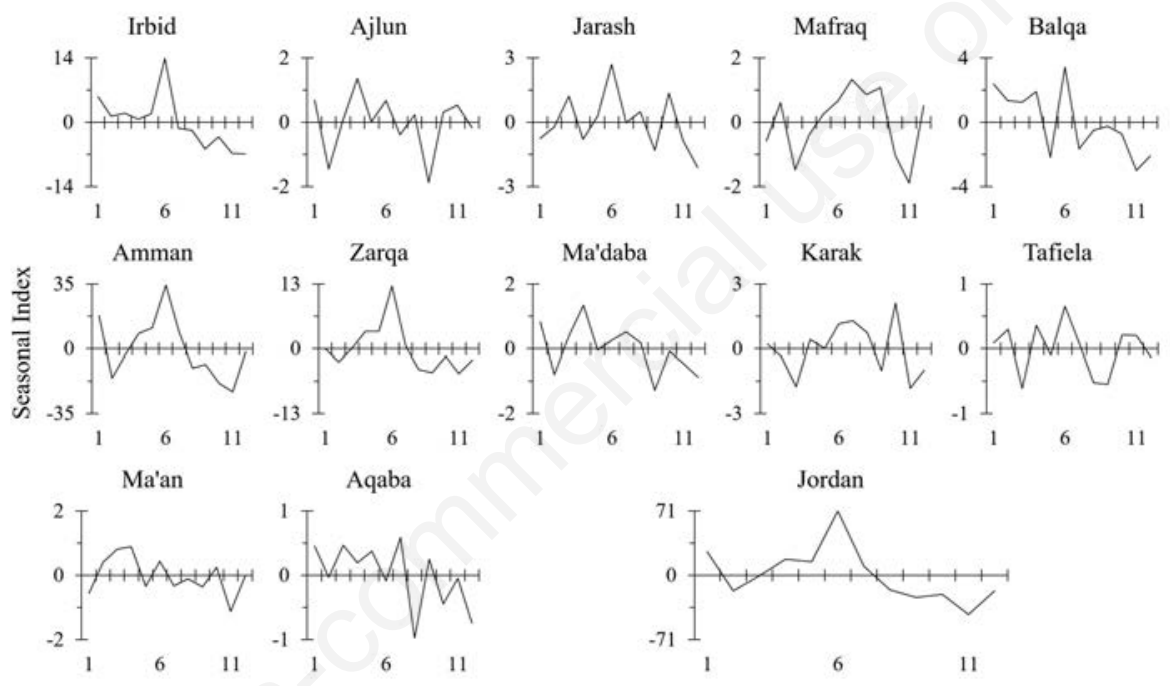

C
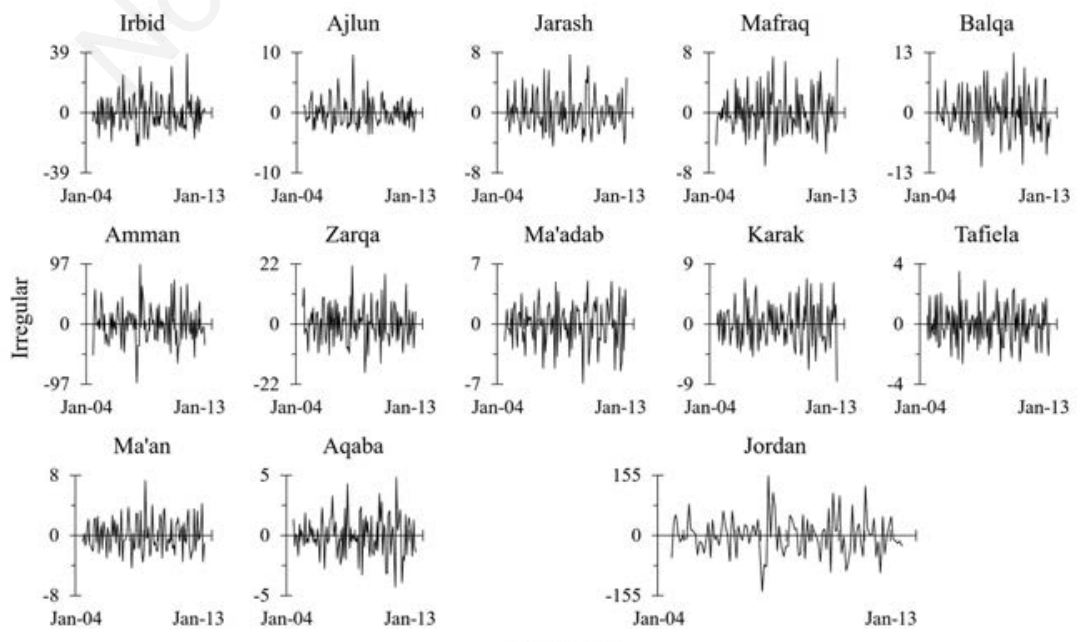

Month-Year

Figure 5. Trend-cycle components (A), seasonal indexes (B), and irregular components (C) resulted from time-series additive seasonal decomposition of the monthly cancer cases counts in Jordan and its 12 governorates in the period 2004-2013. 
The lowest significant rate of increase $(0.006$ (cases/100,000)/month was obtained for Ajlun. For Jordan as a whole, applying the method of least squares resulted in a significant linear fit with a positive rate of change of 1.2 (cases/100,000)/month) indicating an increasing trend. When the retrospective space-time scan statistics analysis was applied on the annual cancer cases counts for Jordan and its 12 governorates, the presence of one significant high-rate cluster, one significant primary low-rate cluster, and two significant secondary low-rate clusters were revealed (Figure 6). The high-rate cluster comprised Amman and spanned the period from 2009 to 2013 with a mean annual cancer crude incidence rate of 100.7 cases/100,000 and a reported cancer case count of 15,113 cases, which was $47 \%$ higher than expected. Except Balqa and Ma'daba, low-rate clusters were formed with respect to the remaining nine governorates. The primary low-rate cluster comprised Mafraq and Zarqa and spanned the period from 2009 to 2013 with a mean annual cancer crude incidence rate of 39.8 cases $/ 100,000$ and a reported cancer case count of 2,855 cases, which was $42 \%$ lower than expected. The first secondary low-rate cluster comprised the three governorates Irbid, Ajlun, and Jarash. The cluster spanned the period from 2009 to 2013 with a mean annual cancer crude incidence rate of 45.3 cases $/ 100,000$ and a reported cancer case count of 3,703 cases, which was $34 \%$ lower than expected. The last secondary low-rate cluster comprised the four governorates Karak, Tafiela, Ma'an, and Aqaba and spanned the period from 2004 to 2008 with a mean annual cancer crude incidence rate of 39.5 cases $/ 100,000$ and a reported cancer case count of 917 cases, which was $42 \%$ lower than expected.

\section{Discussion}

Comparison of the worldwide numbers of cancer incidence (IARC, 2018) with those obtained for Jordan in the present study indicates that cancer incidence in Jordan might be described as being relatively low. Nevertheless, the results presented here are compelling evidence that the incidence of cancer in Jordan, regardless up and down movements and non-linearity, is increasing over time, which is in accordance with that suggested by Torre et al. (2016). These authors indicate that although the cancer risk in high-income countries remains high, it may have reached a plateau for most common cancers or even be decreasing, while these cancers are increasing in several low- and middle-income countries. This might be explained by the fact that high-income countries have shown significant improvements with regard to cancer

\section{Summary of Data}

$\begin{array}{ll}\text { Study Period } & 2004-2013 \\ \text { Number of Governorates } & 12 \\ \text { Total population } & 6,541,268 \\ \text { Total Number of Cases } & 44,741 \\ \text { Annual Cases / 100,000 } & 68.4\end{array}$

High-Rate Cluster Governorates Included Amman

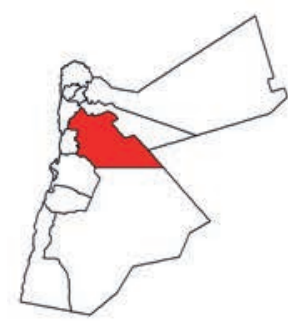

First Secondary Low-Rate Cluster

$\begin{array}{ll}\text { Time Frame } & 2009-2013 \\ \text { Population } & 2,750,247 \\ \text { Number of Cases } & 15,113 \\ \text { Expected Cases } & 10,264.99 \\ \text { Annual Cases / 100,000 } & 100.7 \\ \text { Observed / Expected } & 1.47 \\ \text { Relative Risk } & 1.71 \\ \text { Log Likelihood Ratio } & 1,356.012 \\ \text { p-value } & <0.0000\end{array}$

Governorates Included Irbid, Ajlun, and Jarash

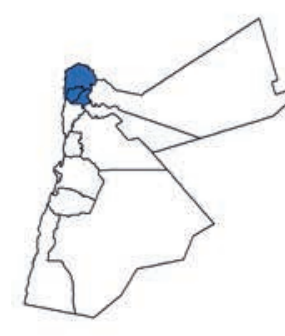

2009 - 2013

$1,498,319$

3,703

$5,592.29$

Expected Cases

Annual Cases / 100,000 45.3

Observed / Expected $\quad 0.66$

Relative Risk

0.63

Log Likelihood Ratio

p-value

$<0.0000$
Primary Low-Rate Cluster

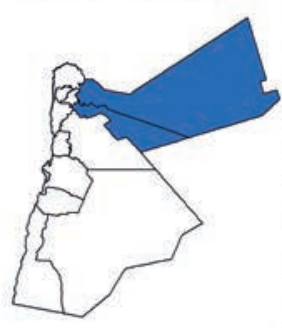

Second Secondary Low-Rate Cluster

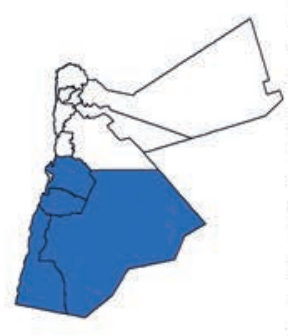

Governorates Included Mafraq and Zarqa

Time Frame

Population

Number of Cases

Expected Cases

Observed / Expected $\quad 0.58$

Relative Risk $\quad 0.55$

Log Likelihood Ratio $\quad 556.654$

p-value

$<0.0000$

Governorates Included Karak, Tafiela, Ma'an, and Aqaba

Time Frame

$2004-2008$

Population

511,355

Number of Cases

917

Expected Cases

$1,588.94$

Annual Cases / 100,000 39.5

Observed / Expected $\quad 0.58$

Relative Risk

Log Likelihood Ratio 173.056

p-value

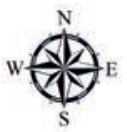

Figure 6. Retrospective space-time scan statistics analysis of the annual cancer cases counts for Jordan and its 12 governorates in the period 2004-2013. 
screening, early detection, and treatment in recent years as well as moved toward reduction of known cancer risk factors. However, although Jordan is a middle-income country showing significant improvements with respect to cancer service, still reveals increasing trends in known cancer risk factors, such as smoking, consumption of unhealthy food, excess body weight, and physical inactivity. People in Jordan are also commonly exposed to environmental, industrial, and agricultural carcinogens, as is the case in many low- and middle-income countries (Al-Tarawneh et al., 2010; Abdel-Razeq et al., 2015; Torre et al., 2016).

This study has revealed that the spatial and temporal characteristics of cancer incidence has a remarkable variation among the 12 governorates of Jordan; an observation that needs further and thorough investigation in order to be explained. One possible explanation might be related to geographic variation in data completeness and quality. However, according to the JCR (JCR, 2016), the completeness and quality of cancer data in Jordan is high and follows international guidelines with minimal variation between governorates. Accordingly, JCR data was accepted in Cancer Incidence in Five Continents series of monographs and databases. The JCR is a population-based cancer registry, which collects data about cancer from all possible sources including public hospitals, teaching hospitals, royal medical services, private clinical sectors as well as laboratories. Data collection follows the same two strategies in all 12 governorates of Jordan. The first is active, which means that the data are collected and abstracted by a trained registry staff through regular visits to all possible facilities. The second is passive according to which the data are sent to the central registry on a regular base by focal-point staff, who represent their own facilities. Some sources provide the data electronically. Naturally, some cases are missed, but almost $95 \%$ of cancer cases diagnosed in Jordan are registered. In addition, due to the fact that most of the facilities for diagnosis and treatment are concentrated in Amman, which hosts more than one-third of the population of the country, most patients present there. Another possible explanation might be related to differences among the 12 governorates with respect to cancer trigger factors, which can be grouped into four groups (Roquette et al., 2017): i) demographics and socioeconomics; ii) individual behaviour; iii) physiological and genetic factors; and iv) environmental issues. Hence, there is a need for further studies aimed at finding differences among the 12 governorates with regard to variations in these trigger factors that might explain the differences noted in the discerned spatial and temporal patterns of cancer incidence among the 12 governorates.

Finally, studying the seasonality of cancer in the present study actually meant studying the seasonality of spotting each case (i.e., diagnosis) followed by its registration. A number of researchers have demonstrated the importance of such studies, specifically with regard to cancer prognosis and survival (Mason and Holdaway, 1994; Lambe et al., 2003; Lim et al., 2006; Porojnicu and Moan, 2008; Moan et al., 2010; Ho et al., 2014). However, no clear patterns could be discerned that could describe the seasonality of cancer incidence in Jordan and its 12 governorates. This might be attributed to the nature of the study which looked at all cancer types together; a fact that might have masked any seasonal influence on some cancer types. Therefore, there is a need to implement well-organized studies aiming at studying the spatial and temporal characteristics of the most common types of cancer in Jordan adjusted for gender and age. Such studies might help in understanding the seasonality of different types of cancer in Jordan and the world.

\section{Conclusions}

Studying the spatial and temporal characteristics of cancer in Jordan and its 12 governorates in the period 2004-2013 lead to the following main conclusions. i) Although cancer incidence in Jordan has been found to be relatively low if compared to other countries in the world, it has been found to be increasing over time, as the case for several low- and middle-income countries. ii) The spatial and temporal characteristics of cancer incidence have been found to be remarkably different among the 12 governorates, with Amman forming a high-rate cluster in which the highest number of cases, highest annual crude incidence rate, highest annual ageadjusted incidence rate, and highest monthly rate of increase values were found. iii) Finally, the seasonality of cancer incidence has been found to be irregular and fluctuating with no clear patterns that could describe its behaviour.

These findings need further in-depth and thorough investigation in order to be explained. Therefore, additional well-designed studies in this specific topic are recommended. These studies should take advantage of the power of GIS as a general framework and platform. This, in turn, should be useful for understanding cancer risk factors and designing and implementing a science-based national action plan for controlling cancer in the country.

\section{References}

Abdel-Razeq H, Attiga F, Mansour A, 2015. Cancer care in Jordan. Hematol Oncol Stem Cell Ther 8:64-70.

Abu-Baker NN, Haddad L, Mayyas O, 2010. Smoking behaviour among coronary heart disease patients in Jordan: a model from a developing country. Int J Environ Res Public Health 7:75164.

Ahmad OB, Boschi-Pinto C, Lopez AD, Murray CJL, Lozano R, Inoue M, 2001. Age Standardization of Rates: A New WHO Standard. GPE Discussion Paper Series: No. 31. World Health Organization.

Ajlouni K, Jaddou H, Batieha A, 1998. Diabetes and impaired glucose tolerance in Jordan: prevalence and associated risk factors. J Intern Med 244:317-23.

Al-Tarawneh M, Khatib S, Arqub K, 2010. Cancer incidence in Jordan, 1996-2005. E Mediterr Health J 16:837-45.

Basheti IA, Qunaibi EA, Bulatova NR, Samara S, AbuRuz S, 2013. Treatment related problems for outpatients with chronic diseases in Jordan: the value of home medication reviews. Int J Clin Pharm-Net 35:92-100.

Bilancia M, Fedespina A, 2009. Geographical clustering of lung cancer in the provinces of Lecce, Italy: 1992-2001. Int J Health Geogr 8:40.

Demoury C, De Smedt T, De Schutter H, Sonck M, Van Damme $\mathrm{N}$, Bollaerts K, Molenberghs G, Van Bladel L, Van Nieuwenhuyse A, 2017. Thyroid cancer incidence around the Belgian nuclear sites, 2000-2014. Int J Env Res Pub Health 14:e988.

Department of Statistics of Jordan (DOS), 2016. Jordan Statistics Yearbook 2016. Jordan: Department of Statistics of Jordan Press.

Haddad MF, Bakkar MM, Abdo N, 2017. Public awareness of common eye diseases in Jordan. BMC Ophthalmol 17:177.

Hansen PC, Pereyra V, Scherer G, 2013. Least Squares Data 
Fitting with Applications. USA: Johns Hopkins University Press.

Hayran M, 2004. Analyzing factors associated with cancer occurrence: a geographical systems approach. Turk J Canc 34:67-70.

Ho A, Gabriel A, Bhatnagar A, Etienne D, Loukas M, 2014. Seasonality pattern of breast, colorectal, and prostate cancer is dependent on latitude. Med Sci Monitor 20:818-24.

Hyndman RJ, Athanasopoulos G, 2014. Forecasting: principles and practice. Available from: https://www.otexts.org/book/fpp

International Agency for Research on Cancer (IARC), 2018. Cancer fact sheets: all cancers excluding non-melanoma skin. Cancer Today, International Agency for Research on Cancer, World Health Organization. Available from: http://gco.iarc.fr/today/fact-sheets-cancers? cancer=29\&type= 0\&sex $=0$ Accessed: 27 August 2018.

Ismail SI, Soubani M, Nimri JM, Al-Zeer AH, 2013. Cancer incidence in Jordan from 1996 to 2009 - a comprehensive study. Asian Pac J Canc P 14:3527-34.

Jaber SM, Ibbini JH, Hijjawi NS, Amdar NM, 2014. An exploratory comparative study of recent spatial and temporal characteristics of cutaneous leishmaniasis in the Hashemite Kingdom of Jordan and Syrian Arab Republic pre-Arab Spring and their health policy implications. Appl Spat Anal Polic 7:337-60.

Jaber SM, Ibbini JH, Hijjawi NS, Amdar NM, Huwail MJ, AlAboud K, 2013. Exploring recent spatial patterns of cutaneous leishmaniasis and their associations with climate in some countries of the Middle East using geographical information systems. Geospat Health 8:143-58.

Jordan Cancer Registry (JCR), 2016. Cancer incidence in Jordan annual reports 2004-2013. Jordan Cancer Registry, NonCommunicable Diseases Directorate, Ministry of Health of Jordan, Hashemite Kingdom of Jordan. Available from: http://www.khcc.jo/section/cancer-registry Accessed: 1 November 2016.

John R, Ross H, 2010. The global economic cost of cancer. American Cancer Society and LIVESTRONG Organization.

Khader YS, 2006. Factors associated with periodontal diseases in Jordan: principal component and factor analysis approach. J Oral Sci 48:77-84.

King Hussein Cancer Center, 2017. Cancer education and awareness, cancer statistics, local statistics. Available from: http://www.khcc.jo/section/local-statistics Accessed: 29 November 2017.

Kinoshita S, Wagatsuma Y, Okada M, 2007. Geographical distribution for malignant neoplasm of the pancreas in relation to selected climatic factors in Japan. Int J Health Geogr 6:34.

Kulldorff M, 1997. A spatial scan statistic. Commun Stat Theory 26, 1481-1496.

Kulldorff M, 2015. SaTScan ${ }^{\mathrm{TM}}$ User Guide for Version 9.4. Calverton, Maryland: Martin Kulldorff, Harvard Medical
School, Boston, Massachusetts, and Information Management Services Inc.

Lambe M, Blomqvist P, Belloco R, 2003. Seasonal variation in the diagnosis of cancer: a study based on national cancer registration in Sweden. Br J Cancer 88:1358-60.

Lim H, Roychoudhuri R, Peto J, Schwartz G, Baade P, Moller H, 2006. Cancer survival is dependent on season of diagnosis and sunlight exposure. Int J Cancer 119:1530-6.

Mason BH, Holdaway IM, 1994. The seasonal variation in breast cancer detection: its significance and possible mechanisms. J Roy Soc New Zeal 24:439-49.

Moan J, Lagunova Z, Bruland O, Juzeniene A, 2010. Seasonal variations of cancer incidence and prognosis. DermatoEndocrinology 2:55-7.

Mohebbi M, Wolfe R, Jolley D, Forbes AB, Mahmoodi M, Burton $\mathrm{RC}, 2011$. The spatial distribution of esophageal and gastric cancer in Caspian region of Iran: an ecological analysis of diet and socio-economic influences. Int J Health Geogr 10:13.

National Cancer Institute (NCI), 2017. About cancer, feelings and cancer. Avalable from: https://www.cancer.gov/aboutcancer/coping/feelings Accessed: 10 November 2017.

Porojnicu AC, Moan J, 2008. Cancer prognosis depends on season of diagnosis. In: Espen Bjertness, ed. Solar radiation and human health Oslo: The Norwegian Academy of Science and Letters.

Roquette R, Painho M, Nunes B, 2017. Spatial epidemiology of cancer: a review of data sources, methods and risk factors. Geospat Health 12:23-35.

Tarawneh M, Arqoup K, Sharkas G, 2011. Epidemiology and survival analysis of Jordanian female breast cancer patients diagnosed from 1997 to 2002. Middle East J Cancer 2:71-80.

Tayyem RF, Bawadi HA, Shehadah IN, Abu-Mweis SS, Agraib LM, Bani-Hani KE, Al-Jaberi T, Al-Nusairr M, Heath DD, 2015. Macro- and Micronutrients consumption and the risk for colorectal cancer among Jordanians. Nutrients 7:1769-86.

Teran-Hernandez M, Ramis-Prieto R, Calderon-Hernandez J, Garrocho-Rangel CF, Campos-Alanis J, Avalos-Lozano JA, Aguilar-Robledo M, 2016. Geographic variations in cervical cancer risk in San Luis Potosi State, Mexico: a spatial statistical approach. Int J Health Geogr 15:161.

Torre LA, Siegel RL, Ward EM, Jemal A, 2016. Global cancer incidence and mortality rates and trends - an update. Cancer Epidem Biomar 25:16-27.

World Health Organization (WHO), 2015. Cancer Control: A global snapshot in 2015, summary of results from the $2015 \mathrm{WHO}$ NCD Country Capacity Survey.

World Health Organization (WHO), 2017. Media Center, Cancer, Fact Sheet, February 2017. Available from: http://www.who.int/mediacentre/factsheets/fs297/en/ Accessed: 7 November 2017. 